\title{
ENHANCEMENT OF AGRICULTURAL EXPORT QUALITY STANDARD (THE CASE STUDY OF TUBTIMJUN ROSE APPLE EXPORT IN RATCHABURI PROVINCE, THAILAND)
}

\author{
Suppara Charoenpoom \\ Kathaleeya Chanda
}

Suan Sunandha Rajabhat University, Bangkok, Thailand

This research had an objective to study the agricultural export quality standards in the case of exporting tubtimjun rose apple from Ratchaburi province, Thailand. This is a qualitative research with the sample of 9 experts in different but related fields which are agriculture, exporting and R\&D. The experts were chosen by means of purposive sampling and the tool used for collecting data was indepth interview.

Our founding is that the agricultural export quality standard in what concerns exporting tubtimjun rose apple from Ratchaburi province, Thailand to China can be divided into 10 aspects which together cover the following: the bottomline quality of tubtimjun rose apple which has 9 indicators, tubtimjun rose apple examination which has 3 indicators, defects of the tubtimjun rose apple which has 2 main indicators and 12 minor indicators, harvesting period after blooming which has 3 indicators, size and the amount of tubtimjun rose apple per kilogram which has 4 indicators, size and weight per tubtimjun rose apple which has 4 indicators, temperature of the storage location which has 3 indicators, deviation in the tubtimjun roseapple size when packaged which has 2 indicators, tubtimjun rose apple's container which has 7 main indicators and 7 minor indicators, and packaging which has 9 indicators.

Keywords: rose apple; quality standard; export; agriculture; Thailand.

\section{Introduction}

Nowadays, Thailand's economic system relies on both import and export along with their increasing competitiveness among the countries of the Asian region since very soon the free trade agreement will play the major role in the economic relations of the region. Thailand have lots of free trade agreements with other countries including China, Australia,

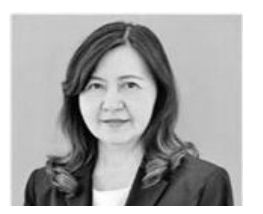

\section{Suppara Charoenpoom}

Asst. Prof. Dr., Ph.D (Innovative Management)

College of Innovation and Management, Suan Sunandha Rajabhat University, Bangkok, Thailand

Research interests - Innovation, Management

E-mail: suppara.ch@ssru.ac.th

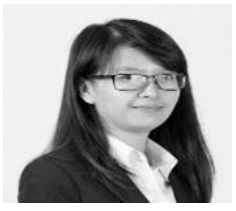

Kathaleeya Chanda

Lecturer in College of Innovation and Management, Suan Sunandha Rajabhat University, Bangkok, Thailand Research interests - Information Technology, Business data

E-mail: katheleeya.ch@ssru.ac.th 
New Zealand etc. (Office of Agricultural Economics, 2015). At the same time, Thailand is still a predominantly agricultural country, thus, exporting agricultural products is one of its main economic activities accounting for over 3-4 bln baht per year. The main markets for Thai agricultural products are China, Vietnam, Indonesia, Japan and Hong Kong. These countries taken together accounted more than $79 \%$ of all exported Thai agricultural product. An additional important and curious fact is that as of today China is not only the main customer of Thailand but also a serious competitor when it comes to fruits' export.

Rose apple is a fruit with a very high trade potential as it creates a lot of demand at many foreign markets and this demand is only increasing with every new year. Tubtimjun rose apple is in special demand by the consumers in China due to its crunchiness and density of the fruit. Tubtimjun rose apple has several major features which make it different from other rose apple types, the key features being the color and the density of fruit. These are the main reasons why tubtimjun rose apples are in demand by Chinese consumers (statistics to prove this point is demonstrated in Tab. 1).

Table 1. Quantity and Value of Tubtimjun Rose Apple Export from Thailand to China, 2009 to 2014

(Source: www.customs.go.th)

\begin{tabular}{|c|c|c|c|c|c|c|}
\hline Year & $\mathbf{2 0 0 9}$ & $\mathbf{2 0 1 0}$ & $\mathbf{2 0 1 1}$ & $\mathbf{2 0 1 2}$ & $\mathbf{2 0 1 3}$ & $\mathbf{2 0 1 4}$ \\
\hline Quantity (kg) & $4,945,075$ & $9,453,806$ & $9,829,076$ & $6,174,923$ & $6,193,204$ & $19,353,553$ \\
\hline Value (Baht) & $55,774,553$ & $95,815,196$ & $115,899,732$ & $183,073,687$ & $185,157,223$ & $275,523,230$ \\
\hline
\end{tabular}

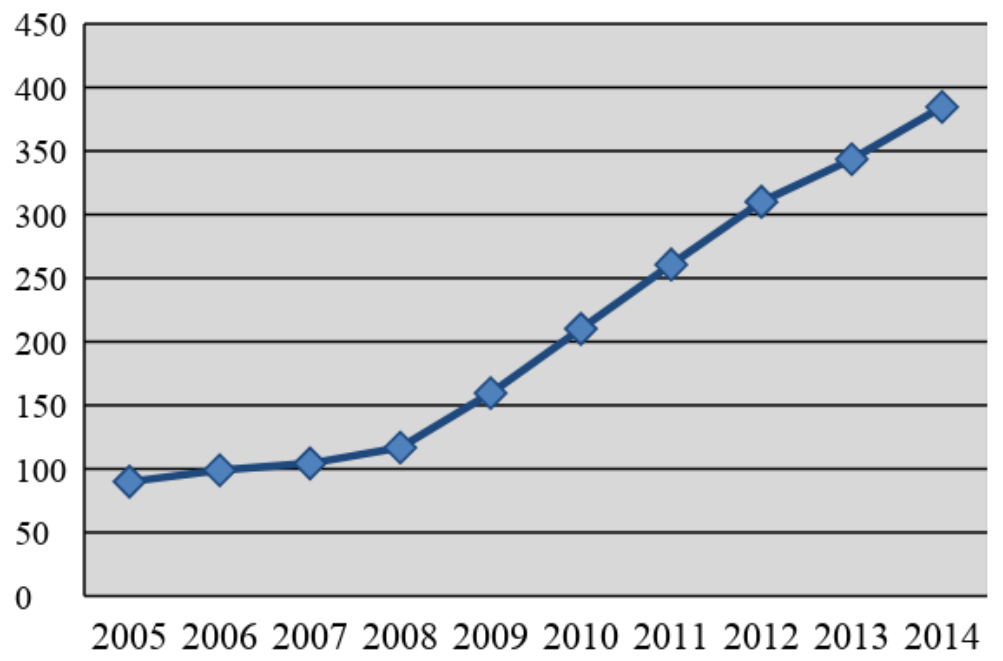

Figure 1. China's Fruit Imports (2005 to 2014)

(Source: General Administration of Quality Supervision, Inspection and Quarantine of the People's Republic of China, 2014)

However, generally speaking the export of agricultural products still has several problems which are climate, fruit flies, the area per farm. Together these and other problems lead to higher costs for management, on the top of which go also taxes and tariffs imposed by the destination countries which hinder international trade in agricultural products even more. 


\section{THE ENHANCEMENT OF THE AGRICULTURE'S EXPORT}

For example, Thai's tubtimjun rose apple used to be suspended from exporting to China a few years ago, and only in 2016 this ban was removed (Uchatrakul, 2015).

Due to this and some other facts, the researchers decided to study the improvement of the agricultural export quality standard on the example of tubtimjun rose apple exports from Ratchaburi province of Thailand to China.

\section{Literature Review}

Prior to this research, the researchers had reviewed the related literature and other research studies applicable to this research and its topic. We have also taken into account the general information on tubtimjun type of the rose apple, various concepts of quality factors which the consumers require along with the quality control issues, and then also the concepts of agricultural standards, and finally the concept of purchase satisfaction and the willingness to repurchase.

Tubtimjun rose apple has a scientific name which is "Eugenia Javanica lam". This fruit originates from Indonesia where it is commonly called "Chitra" (Kehakaset, 2000). It was brought in Thailand only in 1995. Nowadays the quality of Thailand tubtimjun rose apple is already quite high, therefore, there is a steady increase observed in both the planting areas and in the volumes of exports.

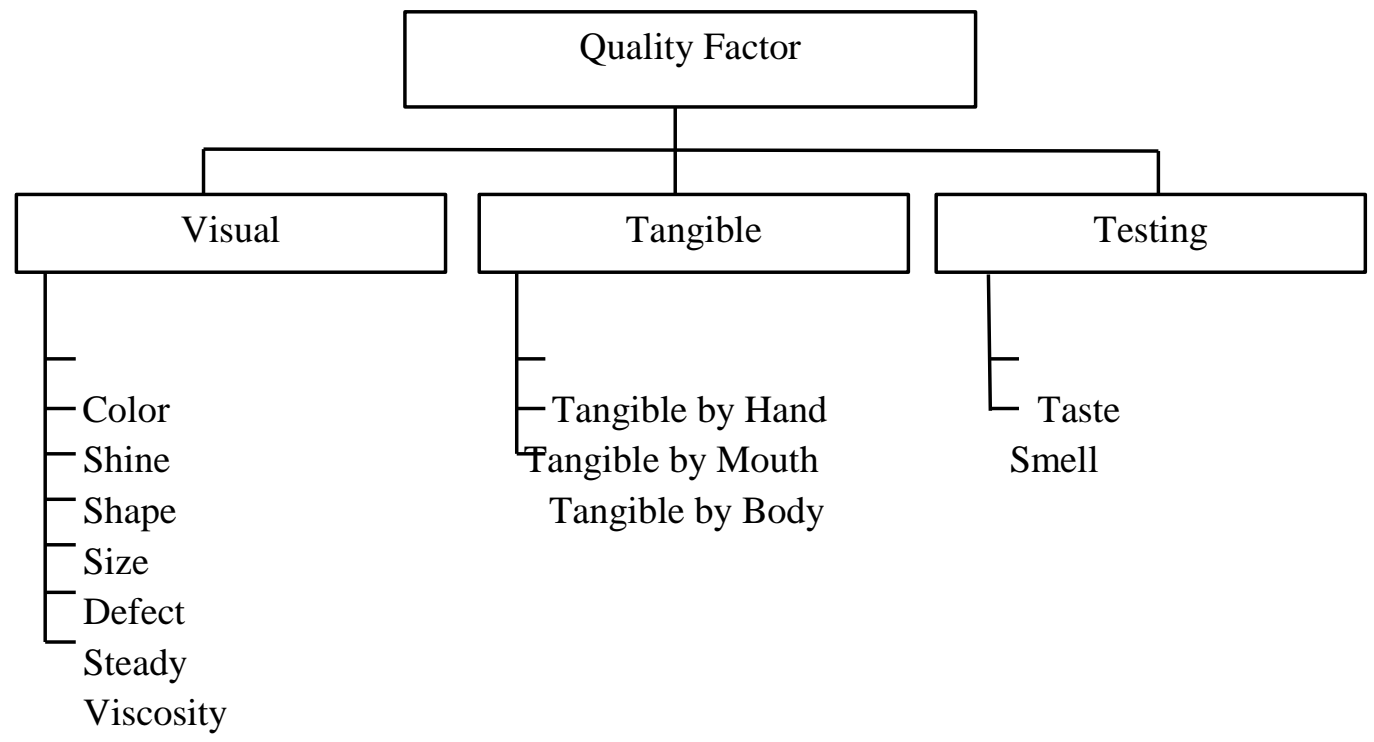

Figure 2. Quality factor observable directly by consumers

(Source: Boonlong, n.d.)

Generally speaking, quality factors are needed by consumers so that to make a decision to accept or not accept the quality of a particular agricultural product. In this decision-making process, the consumer will judge the quality using all five senses: via eyes, ears, nose, mouth, and/or skin. So the quality factors which can be directly observed by consumers can be divided into 3 types as it is shown in Fig. 2 (Boonlong, n.d.). 
All quality factors present in Fig. 2 can be tested by the consumers' 5 senses and the quality factors can be divided into 3 type which are: appearance quality factor, or eye appeal, hand or mouth feel and finally taste and/or smell.

Nowadays, consumers focus increasingly on various health issues which are becoming more and more important for them. On the other hand, the world has moved much closer to the ideas of free trade and borderless trade. Consumers can easily find the same product everywhere. Quality standards thus play a major role in importing, exporting and all production processes.

Nowadays, consumers are paying more attention to their health. The same crops can be purchased from many sources around the world, thus, importance of food standards for agricultural products needs to be constantly emphasized. It is therefore increasingly important that standards used as guidelines for regulating, monitoring and evaluating of production, export and import are strengthened by means of key indicators. The researchers have studied all the concepts and standards applicable to the agricultural crop in question here.We briefly describe them below.

GAP (Good Agricultural Practice) is a set of practices which focus on the environmental sustainability in both economic and social aspects of the farming processes. In Thailand, the Department of Agriculture, Ministry of Agriculture and Cooperatives is the body responsible for certifying according to GAP. Rules and procedures needed to get GAP certification from the Department of Agriculture are limited to such areas as water resources, planting areas, the use of agricultural hazardous materials, storage and transportation of agricultural products within the planting site and the pest control storage (BHC Intertech, 2015; Chansuchai, 2016).

We have also overview the good manufacturing practice (GMP) concept which basically means good practices in food production. Quality assurance systems are enforced into practice and examine by the experts. Requirements to good manufacturing practices cover such key issues such as location of the manufacturing plant, machinery and production equipment, process control, sanitation, maintenance and cleaning, personal hygiene of all workers.

The Codex Alimentarius is a book of standards adopted by the World Trade Organization (WTO) in accordance with the agreement on Technical Barriers to Trade (TBT) and the agreement on the Application of Sanitary and Phytosanitary Measures (SPS). This collection of standards is basically an attempt to participate in compliance between international standards and national quality standards.

In addition, the National Bureau of Agricultural Commodities and Food Standards established the quality standard specifically for the rose apple "Syzygium samarangense" which describes specifically quality, size, tolerance, marking and labeling, signs, contaminants, toxins, hygienic residues, and how to adopt all the analytical and sampling methods after the detection of a diseases and/or fruit flies. China has provided a measure and a special standard to ensure that those who are sending their agriculture product have been certified by Chinese inspection authorities and thus have all the rights to import their product into China. This standard includes, inter alia, the direct examination of both inside and outside the basket with rose apples. The key parameter is that the basket must be free from fruit flies, worms, fungi etc. (Quality Control and Quarantine Bureau of China, 2014).

After the thorough literature review and the preliminary survey the researchers have decided to apply the Codex Alimentarius and the standard of agricultural products of the 


\section{THE ENHANCEMENT OF THE AGRICULTURE'S EXPORT}

National Bureau of Agricultural Commodity and Food Standards (2011) while setting the guidelines for improving the quality of agricultural product for export taking the case study of tubtimjun rose apple exported from Ratchaburi province to China.

\section{Methodology}

This research is the qualitative research and the researchers have used indepth interviews with the sample group which can be divided into 3 groups: 3 tubtimjun rose apple's farmer that have at least 5 years of experience in the related field, 3 entrepreneurs who are experts in sizing and sorting the tubtimjun rose apples and also 3 government officers who are experts in agricultural production overall and have at least 5 years of experience in the field.

There are 2 types of tools the researchers used in this study. The first tool is the interview which was formulated basing on the Codex Alimentarius, and the other tool is testing the appropriability level with 9 experts following by the index of concordance (Tirakanan, 2000).

\section{Results}

The results from the study on Ratchaburi tubtimjun rose apple's qualification so that to be exported to China can be broken down into 10 aspects which are as follows:

1) Bottomline quality of rose apple which contains 9 indicators, namely:

1.1) The rose apple is in good shape;

1.2) The rose apple is fresh;

1.3) The rose apple's skin is clear and shiny;

1.4) The color is red;

1.5) The rose apple is clean;

1.6) The rose apple's taste is fine;

1.7) The rose apple is odorless;

1.8) The rose apple is not bitten by fruit flies;

1.9) There are no defect marks.

2) Rose apples' examination that is done according to 3 indicators which are:

2.1) The rose apple arrives at the sizing and packaging site still in the original farmer's plastic bag;

2.2) Every rose apple has passed the quality check twice;

2.3) The rose apple must pass the sizing process.

3) Defects of rose apples have 2 main indicators and 12 minor indicators which are:

3.1) The defect which leads to the ban on exporting to China has the following 12 minor indicators:

3.1.1) bite mark;

3.1.2) pierce mark;

3.1.3) hole;

3.1.4) defect marks;

3.1.5) heavy scratches; 
3.1.6) bruised mark;

3.1.7) broken mark;

3.1.8) the rose apple is watery;

3.1.9) rotten roseapple;

3.1.10) striped mark on the roseapple skin;

3.1.11) bad shape;

3.1.12) different color (not red).

3.2) The only defect which still allows exporting to China is a slight scratch mark.

4) Harvesting period after blooming is covered by 3 indicators which are:

4.1) between 80-90 days;

4.2) 80 days if the temperature has been too hot;

4.3) 90 days if the temperature has been too cold.

5) Size and the amount of rose apples per kilogram - 4 indicators:

5.1) Number 1 (L or 1A) - around 11-12 rose apples per kilogram;

5.2) Number 2 (LL or 2A) - around 9-10 rose apples per kilogram;

5.3) Number 3 (XL or 3A) - around 7-8 rose apples per kilogram;

5.4) Number 4 (XXL or 4A) - around 5-6 rose apples per kilogram.

6) Size and weight per one rose apple - also 4 indicators which are:

6.1) Number 1 (L or 1A) - the weight of 80-100 grams for one rose apple;

6.2) Number 2 (LL or 2A) - the weight of 100-120 grams for one rose apple;

6.3) Number 3 (XL or 3A) - the weight of 120-150 grams for one rose apple;

6.4) Number 4 (XXL or 4A) - the weight of more than 150 grams in one rose apple.

7) Temperature has 3 indicators which are as follows:

7.1) Temperature before sizing and packaging site is standard room temperature and the rose apple must be in a plastic bag;

7.2) The temperature when sizing and packaging is between $23-25 \mathrm{C}$; temperature.

7.3) The temperature when transporting to the Suvarnabhumi airport is room

8) Deviation in the roseapple size when packaging has 2 indicators which are:

8.1) less than $10 \%$;

8.2) the size is only 1 class larger or smaller.

9) Package has 7 main and 7 minor indicators which are:

9.1) The package is brand new plastic rectangular container of A grade fully covering the product;

9.2) The package size are $36 \mathrm{~cm}$ in width, $49 \mathrm{~cm}$ in length and $21 \mathrm{~cm}$ in height;

9.3) The package is clean and odorless;

9.4) There is white paper cover inside every basket;

9.5) The bottom of the basket has a plastic bumper (34 $\mathrm{cm} \mathrm{x} 44 \mathrm{~cm})$;

9.6) The basket prevents access for fruit flies;

9.7) There is a label placed on the basket containing the following information: 


\section{THE ENHANCEMENT OF THE AGRICULTURE'S EXPORT}

9.7.1) Name of the Exporting Company;

9.7.2) Fruit Type;

9.7.3) Packing House Register Number (according to GMP);

9.7.4) Orchard Register Number (according to GAP);

9.7.5) Packing date;

9.7.6) Export to the People's Republic of China;

9.7.7) 输往中国人民共和国 (which also means “Export to China”).

10) Packaging has 9 indicators which are:

10.1) The tubtimjun rose apple passed the quality check and sizing and is wrapped by thin white paper $(25 \mathrm{~cm} \times 25 \mathrm{~cm})$;

10.2) There is a grade A foam net wrap after the paper wrap of tubtimjun rose apple;

10.3) The tubtimjun rose apples are places orderly in the basket in 3 layers (each layer has 4 rows);

10.4) There is a plastic bumper $(34 \mathrm{~cm} \times 44 \mathrm{~cm})$ between every row of rose apples;

10.5) The net weight of tubtimjun rose apples is 8 kilograms per half a basket;

10.6) There is a white plain paper covering the top of every basket;

10.7) There is a plastic bumper $(34 \mathrm{~cm} \times 44 \mathrm{~cm})$ covering on the top after the white plain paper;

10.8) There is a cover above the fully packed basket;

10.9) There are 2 plastic ropes tie between the cover and the basket on every side.

\section{Conclusions and Discussion}

As the researchers have applied the Codex Alimentarius and the roseapple qualification index of the National Bureau of Agricultural Commodity and Food Standards (ACFS) as the main standards of this research, our conclusion is that there are 10 quality indices which are in the similar pattern as to the Codex Alimentarius. This conclusion is similar to the conclusions found in other research studies that had already described in detail the quality factors which the consumers can easily observe themselves (Narudom Boonlong, n.d.). Also we can observe a great deal of similarity with the standards of Good Agricultural Practice (GAP) and Good Manufacturing Practice (GMP).

The researchers have experienced certain obstacles and limitations in the course of data collection which are mainly caused by the fact that the entrepreneurs directly involved in sorting and packaging of tubtimjun rose apples were not fully ready and eager to cooperate with the researchers. The problem was that these entrepreneurs were afraid that their own sorting and packaging site is not in the perfect condition so that to meet with the GMP standards, thus, they were unable to be completely sincere about the needed description.

\section{Suggestion}

From the findings of this research we have reached the conclusion that entrepreneurs working in this field should be constantly developing so that to comply with the good manufacturing practice standards. Moreover, the Ministry for Agriculture and Cooperatives should be more proactive in helping these entrepreneurs to solve the problems with the quality of their goods and management overall. 


\section{Acknowledgement}

Thailand.

This research has been funded by Suan Sunandha Rajabhat University, Bangkok,

\section{References:}

BHC Intertech (2015). http://www.bscpest.com/site/ipm.htm.

Boonlong, N. (n.d.). Quality Control. Ministry of Agriculture and Cooperatives.

Chansuchai, P. (2016). Expanding Chance of Palm Oil Market into ASEAN Community: Case Study of Choomporn Palm Oil Cooperative. Bangkok: Suan Sunandha Rajabhat University.

Kehakaset (2000). Investment in Plant. Bangkok: Songsittiwan Co., Ltd.

Office of Agricultural Economics (2015). Annual Performance Report 2014. Bangkok: Ministry of Agriculture and Cooperatives.

Quality Control and Quarantine Bureau of China (2014). Overall Testing and Suspension for Fruit Importing in China. Quality Control and Quarantine Bureau of China.

The National Bureau of Agricultural Commodity and Food Standards (2011). Standard of Rose Apple. The National Bureau of Agricultural Commodity and Food Standards.

Tirakanan, S. (2000). Research Methodology in Science. Bangkok: Ramkhamhaeng University.

Uchatrakul, O. (2015). Study Causes Thai's Tubtimjun Roseapple use to be Suspension to China. Ministry of Agriculture and Cooperatives.

Paper submitted

Paper accepted for publishing

Paper published online
18 March 2019

22 May 2019

25 June 2019 